Locher, M. A., \& Graham, S. L. (2010). Introduction to Interpersonal Pragmatics. In M. A. Locher \& S. L. Graham (Eds.), Interpersonal Pragmatics (pp. 1-13). Berlin: Mouton.

\title{
1. Introduction to interpersonal pragmatics
}

\author{
Miriam A. Locher and Sage L. Graham
}

\section{The interpersonal aspect of language and the aim of this handbook}

This collection of papers within the Handbook of Pragmatics series deals with the interpersonal or relational ${ }^{1}$ side of language in use in that it explores in what ways social actors use language to shape and form relationships in situ. Before we outline this particular focus in more detail, we wish to position this approach within the field of pragmatics as such. Pragmatics, as a discipline, has a long and complex history, with what some would call an "identity problem" from its earliest conception to the present day. Crystal (1997: 120) says that pragmatics is "not as yet a coherent field of study," and, although he made this observation over ten years ago at the time of this writing, it can be argued that pragmatics is still just as diverse as it was then. Verschueren (2009: 9) says that "pragmatics sometimes looks like a repository of extremely interesting but separable topics such as deixis, implicature, presupposition, speech acts, conversation, politeness, and relevance." Many, in fact, associate the field of pragmatics with Speech Act Theory (Austin 1962; Searle 1969). Others (e.g., Schiffrin 1994) link pragmatics most strongly to Grice's (1975) cooperative principle. The label 'pragmatics' has also been assigned, however, to a much broader array of research. Cummings (2005: 1) observes that "pragmatics is significantly informed by a range of academic disciplines" and although this breadth has been viewed as problematic by some (e.g., Blakemore 1992; Davis 1991) others advocate a broader approach. Verschueren (2009), for example, interprets pragmatics as

[A] general functional perspective on (any aspect of) language, i.e. as an approach to language which takes into account the full complexity of its cognitive, social, and cultural (i.e. meaningful) functioning in the lives of human beings. (Verschueren 2009: 19, italics removed)

The strength of this definition, we believe, is that it allows us to examine the complexity of language use from a rich array of perspectives, and, consistent with this, our goal here is to take advantage of the multi-faceted nature of pragmatics. We thus use a definition of pragmatics in the European tradition, i.e., a view that includes the study of language in use from a social and cultural point of view, rather than a definition of pragmatics in the more narrow sense (Taavitsainen and Jucker, 2010; Jucker 2008).

Having said this, the term 'interpersonal pragmatics', which features in the title of this volume, is not to be understood as a term for a theory in competition with theoretical approaches to the study of language in use such as interactional sociol- 
inguistics, conversation analysis, discourse analysis, critical discourse analysis, systemic functional grammar, or others, which have traditionally studied the interpersonal aspect of language as well. Instead, what we aim to achieve in this collection is to bring together researchers from different theoretical strands and fields in order to discuss topics and themes that are relevant to the study of the interpersonal side of language in use; we therefore take a perspective within pragmatics that focuses in particular on the aspect of relationships. In choosing the chapter topics for this volume, we attempted to explore facets of interaction between social actors that rely upon (and in turn influence) the dynamics of relationships between people and how those relationships are reflected in the language choices that they make. The term 'interpersonal pragmatics' is used to designate examinations of the relational aspect of interactions between people that both affect and are affected by their understandings of culture, society, and their own and others' interpretations. We hope that this compilation is relevant for researchers and students alike who are interested in this particular focus of linguistics.

In order to illustrate the importance of the relational aspect of language in more detail and to explain the focus of this volume further, we will briefly touch on a number of findings derived from previous linguistic research. Recognizing that much of the language variation that we witness is caused because people adjust their language to their addressees and the situation in order to achieve interpersonal effects, we posit that it is of interest to give this part of language use center stage here. As a case in point, consider Holmes' (1992) example taken from her well known An Introduction to Sociolinguistics:

(1) Every afternoon my friend packs her bag and leaves her Cardiff office at about 5 o'clock. As she leaves, her business partner says goodbye Margaret, (she replies goodbye Mike) her secretary says goodbye Ms Walker, (she replies goodbye Jill) and the caretaker says Bye Mrs Walker (to which she responds goodbye Andy). As she arrives home she is greeted by Hi mum from her son, Jamie, hello dear, have a good day?, from her mother, and simply you're late again! from her husband. Later in the evening the president of the local flower club calls to ask if she would like to join. Good evening, is that Mrs Billington? she asks. No, it's Ms Walker, but my husband's name is David Billington, she answers. What can I do for you? Finally a friend calls Borodar Meg, how's things? (Holmes 1992: 3)

What we witness here is that one and the same person is being addressed with different terms and adjusts her lexical choices herself when saying hello and goodbye to her conversational partners depending on the role she and her addressees take on in the contexts at hand (business partners, employer/secretary, employer/caretaker, mother/son, wife/husband, friends, strangers). The choice of lexemes on both sides is influenced by factors such as power, distance and closeness, and affect between her and the addressees as well as the expectations about appropriate conduct linked to roles in particular situations. The speech acts of saying hello and saying goodbye thus receive different instantiations depending on the factors mentioned. We could 
argue that the informational content remains the same in all cases, i.e., the speakers wish to initiate their conversations or terminate their dealings with each other for the time being and express this by a conventionally recognized sequence of exchanges, that, in Searle's (1969: 65) words, count "as a courteous indication of recognition of the hearer". At the same time, the ways in which the interactants achieve this exchange tells us something about how the conversational partners position themselves vis-à-vis each other. They thus index relationships by means of their use of language: "Linguistic variation can provide social information" (Holmes 1992: 4).

The above example and brief explanation will be familiar to many readers; it clearly illustrates the importance of language in the creation of relationships and how those relationships affect language use in turn. Many strands of research have investigated these interpersonal effects and some of these strands of research are listed below. For example, Watzlawick, Beavin and Jackson (1967: 54) maintain that "[e]very communication has a content and a relationship aspect such that the latter classifies the former and is therefore a metacommunication." Furthermore, the content and relational aspects of language are impossible to separate entirely (Fill 1990). There are certain practices that primarily focus on "optimally efficient transmission of information" (Brown and Yule 1983; Lakoff 1989), i.e., what Kasper (1990: 205) terms transactional discourse, and there are other practices that have as their "primary goal the establishment and maintenance of social relationships", and constitute interactional discourse (Kasper 1990: 205). We nevertheless cannot entirely separate the content from the relational aspect in these instances. In the above example, we can see that the exchanges between the business partners (goodbye Margaret/goodbye Mike), secretary and employer (goodbye Ms Walker/goodbye Jill) and caretaker and employer (bye Mrs Walker/goodbye Andy) achieve the act of leave-taking and also shape relationships between the participants by foregrounding the hierarchical relationships through the use of more for$\mathrm{mal} / \mathrm{less}$ formal address terms.

With respect to Example (1) it is important to point out that relational aspects in language use are not only conveyed in the use of lexical alternatives, but may also manifest themselves in syntactic and phonological choices. Interactants may signal (consciously or subconsciously) that they belong to a certain social class or group by their use of language. For example, non-standard syntactic patterns in the case of dialects may index social and regional belonging. Research in sociolinguistics ${ }^{2}$ has further established that the use of language is influenced by a variety of factors such as age, gender, ethnicity or socio-economic background. Ultimately, such language use creates in-groups and out-groups and as such shapes relations between people. As a result, the combination of these choices add to a person's linguistic identity construction and thus combine to position a person vis-à-vis others.

The latter point highlights that the relational aspect of language is closely linked to how people shape their identities. Seminal work on linguistic identity 
construction is carried out, among others, by psychologists such as Davies and Harré (e.g., 1990) in their positioning theory, conversation analysts like Bucholtz and Hall (2005) in their sociocultural linguistic approach, or De Fina (2003), who uses a discourse analysis framework when studying narratives and identity (cf. De Fina's Chapter 8 in this handbook). Further theoretical approaches to the study of how people create relational meaning in interaction by means of language can be found in communication studies and social cognitive linguistics (which is also influenced by social psychology) (cf. Chapters 6 and 7).

Brown and Levinson's $(1978,1987)$ politeness theory is a further approach that has addressed the relational aspect of language and in particular the factors of power and distance (in addition to contextualizing factors) ${ }^{3}$ that play a crucial role in the study of language in use. Their approach is an attempt to systematically take into account the relational factors that hold between interactants and that shape the decisions on language choice the interactants make in situ. Their work and work inspired by them in the last decades will be discussed in detail in Chapters 2 to 5 of this volume and will be further introduced below.

As this cursory glance at some of the linguistic strands of research has shown, the relational aspect of language is recognized as important and has received attention in the past but it still deserves our attention today. While much of the research just mentioned may not be explicitly positioned in the field of pragmatics by the scholars themselves, we posit that it contributes to the study of language in use. Taking advantage of this multi-faceted nature of pragmatics we invited scholars from different research traditions to explore the interpersonal aspect of language in use from different perspectives. The overall structure of the volume consists of three parts: Part I deals with a selection of theoretical approaches to interpersonal language issues, looking at the politeness and impoliteness frameworks, approaches to interpersonal interpretation from communication studies and cognitive linguistics, and the key issues 'gender' and 'identity'; Part II introduces classical issues in empirical research with the focus on linguistic strategies employed for interpersonal effects; Part III sheds light on interpersonal issues in a number of different discourses and practices, i.e., the focus is on the practices and the many different linguistic strategies that are employed therein. In what follows, we will raise a number of theoretical issues by introducing the structure and chapters of the handbook in further detail.

\section{Part I: Theoretical approaches to interpersonal pragmatics}

The first part of this handbook is dedicated to 'theoretical approaches to interpersonal pragmatics' and thus takes up different approaches to and different foci on the relational aspect of language in use. The first subsection of Part I deals with 'approaches to politeness and impoliteness'. To include im/politeness research in 
this volume seems almost a given since many readers may first think of politeness theory when considering interpersonal or relational issues in language. Four chapters are dedicated to this research strand. Brown and Levinson's $(1978,1987)$ seminal study exemplifies the attempts of the researchers to include the situation and the interactants' relations in the study of how im/politeness is negotiated. They have given currency to the metaphor of 'face' and so-called 'face-threatening acts'. In their framework, face is "the public self-image that every member wants to claim for himself [sic.]" (Brown and Levinson 1987: 61), while face-threatening acts are "acts that by their nature run contrary to the face wants of the addressee and/or of the speaker" (Brown and Levinson 1987: 65). The researchers then demonstrate how people systematically redress or avoid face-threatening acts, a process which they equate with politeness. Their study is influential to the present day and can easily be argued to be the starting point for most research in the field of politeness since its publication. This is even true for work that takes a distinctly different point of view since work in this field cannot but make reference to this seminal study. For this reason, Chapter 2 by Maria Sifianou, entitled 'Linguistic politeness: Laying the foundations', re-examines this classic work by appraising its advantages and drawbacks, looking back over three decades of research. She also includes a discussion of other early work, such as Lakoff's (1973) Rules of Politeness or Leech's (1983) Politeness Principle.

Chapter 3 by Richard J. Watts, 'Linguistic politeness theory and its aftermath: Recent research trails', then takes up and explores the developments in politeness research since these early approaches. There are two issues that appear to be most noteworthy. On the one hand, there is a current debate to what extent researchers should take a first order (interactant-informed/emic) or a second order (theoretical/ etic) approach to studying politeness (cf., e.g., Locher and Bousfield 2008; Bousfield, this volume). This debate on methodology is important since it has again brought movement into this field of research. On the other hand, both first and second order researchers have started to broaden the field of study in that politeness is no longer the only object of study. For example, the term 'relational work', as used by Locher and Watts (2008: 96), "refers to all aspects of the work invested by individuals in the construction, maintenance, reproduction and transformation of interpersonal relationships among those engaged in social practice." Studies in recent years thus focus no longer predominantly on mitigating facework, but on face-enhancing, face-maintaining, as well as face-aggravating/damaging behavior.

Some of the reactions to the vast numbers of politeness studies inspired by the early approaches to politeness research called forth reactions from researchers who investigated non-Western, and especially Asian languages (e.g., Matsumoto 1988; Mao 1994). Early on, there was criticism of the notion of face because it was argued to be conceptualized as an Anglo-Western, individualistic concept, at the exclusion of cultures that would favor a more group-oriented and less individualistic understanding of face. As a result, research on Asian languages furthered our 
understanding of politeness in general and asked the research community to critically re-examine notions of universality. For this reason, Chapter 4 by Shigeko Okamoto, 'Politeness in East Asia', is dedicated to this research tradition. Okamoto takes up these early criticisms and traces research to the present in order to show how politeness studies have advanced in these language contexts.

Finally, Chapter 5 by Derek Bousfield focuses on 'Researching impoliteness and rudeness: Issues and definitions', i.e., on relational work that disrupts the balance of interpersonal communication and is face-damaging or face-aggravating. Research into this part of interpersonal pragmatics has only recently picked up momentum within the field of politeness studies (cf. the introduction to the edited collection on impoliteness by Bousfield and Locher 2008). The scope of interest has therefore been enlarged to no longer only look at the mitigation of face-threatening acts, but also to investigate intentional as well as accidental face-damaging behavior. In his chapter, Bousfield, focusing on the English language, critically looks at current first and second order research and argues for a second order approach, fed by first order information.

The second sub-section in the theoretical part of this handbook contains two papers. Chapter 6 by Robert B. Arundale is entitled 'Relating'. It gives a voice to those researchers in communication studies and social psychology who have worked on interpersonal relations for a long time, but who have generally been rarely read and received in the linguistics (politeness) literature. Arundale opens our eyes to further important methodological issues and the need of working with clearly defined terminology when studying how people use language within relationships.

Chapter 7 by Andreas Langlotz is named 'Social cognition'. The author proposes that scholars of interpersonal pragmatics can benefit from taking research approaches and results from cognitive psychological, cognitive-linguistic, and socio-cognitive theories on board. The result of this merging of interests is called 'social cognition' and firmly takes the situated and dynamic dimension of language in use into account when explaining how individuals create meaning and make sense of their identities, roles, and interpersonal relationships.

The last two chapters in Part I are dedicated to two important themes in interpersonal pragmatics: identity and gender. Both topics represent major trends in linguistic research that deal with interpersonal issues. The construction of identity and gender as one aspect of $i^{4}$ - is by definition linked to positioning vis-à-vis others and is thus interpersonal. Since neither gender nor identity can be argued to be linguistic strategies (discussed in Part II of this handbook) or contexts/discourses (discussed in Part III), they are covered here. In Chapter 8, 'The negotiation of identities', Anna De Fina reviews the literature on how language contributes to creating identities within the social constructivist framework, i.e., within a view that sees identity not as a fixed given, but as emerging and being constructed in interaction. She identifies three main research strands (CA inspired ap- 
proaches/autobiographical approaches/sociolinguistically oriented approaches) and highlights their respective methodological and theoretical choices.

Chapter 9 by Louise Mullany is then dedicated to 'Gender and interpersonal pragmatics'. The notion of gender is seen as (just) one aspect important in identity construction and is thus considered relevant with respect to how people use language and index relational meaning. This topic has received much attention within pragmatics so that Mullany starts out with a review of different research traditions. She then proceeds to demonstrate how research on politeness and gender can be merged and thus makes a link to the first section of the handbook.

\section{Part II: Linguistic strategies for interpersonal effects}

Part II introduces a selection of linguistic strategies that interactants use to negotiate relational issues: Mitigation, respect and deference, swearing and humor. The argument is that these linguistic strategies can fulfill different social and interpersonal functions. The chapters review how the linguistic strategies are employed and what factors play a role in determining their interpersonal effects. The attention is thus on linguistic choices that have been found to be associated with relational work. We are of course aware that these linguistic strategies are multifunctional and that the list is far from exhaustive. We have opted for four concepts that have been well documented in research and hope to highlight their relational impact on language in use by offering reviews of the current state of the art.

Chapter 10 by Stefan Schneider is dedicated to mitigation - probably one of the best-studied strategies within interpersonal pragmatics. Schneider enlightens us with respect to the interpersonal side of mitigation and offers a plethora of terminology derived from the extensive literature (disclaimers, bushes, hedges, shields, parenthetical verbs, tag questions, etc.) in order to enlarge and improve our understanding of the processes involved.

Michael Haugh turns our attention to the notions of respect and deference in Chapter 11 and links back to the chapters on politeness and impoliteness at the beginning of the handbook. He shows that some of the work inspired by early politeness research conflated respect and deference (in the form of honorifics) with politeness, while others have called for treating the concepts separately. Haugh argues for studying them within the broader framework of relational work as such.

Karyn Stapleton deals with swearing in Chapter 12 by reviewing how this strategy can bear on relationships due to its psychological, social and interpersonal functions. She discusses the taboo areas from which swear-words are taken and shows that, while swearing is considered a risky activity that might call forth censure, it can also be used, for example, as a strategy to reinforce in-group solidarity. Stapleton makes links to the topics of gender and identity construction and discusses research on the notion of gendered swearing. 
Finally, Stephanie Schnurr discusses the multifunctionality of humor and how it relates to the creation of interpersonal meaning in Chapter 13. She shows that humor can be employed to reinforce solidarity, create a friendly atmosphere, mitigate, demarcate groups (in-group/out-group) and reinforce existing power relations (or resist and challenge them); sometimes more than one function may cooccur. In addition, Schnurr highlights the social constraints on the use of humor, discusses how social factors such as gender, intimacy, culture, or ethnicity play a role in the creation of interpersonal effects, and introduces methodological challenges in the study of humor.

\section{Part III: Interpersonal issues in different contexts}

While Part II focuses on specific linguistic strategies and draws on several discourse contexts to explain them, Part III gives central stage to particular contexts and then looks at the (potentially many) linguistic strategies employed for creating relational effects in these discursive practices. The contexts and discourses chosen to be discussed are the workplace, health discourse, legal discourse, political discourse, and the discourse of dating ads. Although this list provides only a snapshot of possible topics, each of these areas has received a great deal of attention as contexts in which interpersonal negotiations of power and solidarity can have a tremendous impact, not just on expectations about appropriateness on an interpersonal level, but also within larger social structures. In each of the chapters, the focus is on the interpersonal issues that emerge as shaping the discursive practices (e.g., power, solidarity, delicateness of topics, interactional roles, etc.). The chapters include reviews of the field as well as reports on empirical research.

Chapter 14 by Bernadette Vine examines 'Interpersonal issues in the workplace'. Using the notions of power and solidarity as a foundation, she explores strategies (small talk, narrative, and humor) employed by individuals engaging in 'social talk' in the workplace to negotiate their identities and relationships within their workplace roles. She also explores the interpersonal functions of turn-taking, face threatening acts, and interpersonal markers in workplace transactional talk. By engaging in an examination of both the social aspect of workplace interaction as well as the transactional component, Vine gives us a more comprehensive view of the connections between interpersonal communication strategies and power as they relate to the negotiation of workplace identities and interpersonal relationships.

In Janet Cotterill's chapter on 'Interpersonal issues in court', the author notes that previous research on forensic linguistics has focused on turn-taking and the pre-ordained and prescriptive rules that govern interaction in the courtroom, but has not explicitly addressed the relationships between the participants from the 
perspective of power. Drawing on the tenets of Gricean pragmatics and the cooperative principle, she explores the fundamental rules of courtroom behavior and examines the strategies and practices of witnesses who appear to rebel against these "interactional rules". She goes on to explore the relational strategies that witnesses employ and what consequences might exist for the witnesses who resist and rebel against the (sometimes unspoken) dictums of what is considered appropriate language use in this context.

Boyd Davis provides a close examination of 'Interpersonal issues in health discourse' in Chapter 16. Her examination not only explores the ramification of communicative practices and assumptions for speakers with Alzheimer's, it also poses a key question in the development of health discourse research (namely how to best connect the wide array of researchers who are studying interactional and interpersonal issues in medical encounters). Researchers in this area run the gamut from linguists to medical doctors interested in communicating more effectively with their patients (although not all of them focus on the interpersonal/relational component of medical interactions). This is important for two reasons: (1) each of the groups that Davis identifies has different research goals (and therefore hopes for different outcomes and applications for the research that they do), and (2) because there is little dialogue between the various disciplines, the application of research findings may be limited. In other words, if researchers are not aware of findings from other disciplines, they cannot take advantage of this (potentially) rich resource. Research findings uncovered by medical doctors, for example, may never reach the linguistics community (and vice versa) because the journals where results are published are rarely read by researchers from other disciplines/other perspectives. This shortcoming has striking implications for treatment, and Davis uses examples from Alzheimer's talk to illustrate this.

As with the other contexts discussed so far, political discourse is another area where the rules for interaction are intricately intertwined with power relations. In José Luis Blas Arroyo's chapter on 'Interpersonal issues in political discourse', the author examines the ways that conflict management and the enactment of power and authority are used by candidates in navigating the complex relationships they have with their audiences. As Blas Arroyo notes, political discourse is particularly complicated with regard to interpersonal relationships because of the multi-layered and overlapping web of audiences. Politicians must manage their adversarial relationships with other candidates, attend to their communication with the voters (who may be the ultimate audience for any politician's talk), and strategically interact with the media (and its ability to craft a persona for the candidate who might or might not be appealing to its own (the media's) audience or the politician's envisioned audience (voters)).

Finally, Carol Marley's chapter puts issues in the discourse of dating ads 'under the microscope'. In fact, dating ads can be argued to be an ideal forum to investigate the connection of language and identity construction, since the ads function as 
the first means of contact between interactants who want to start a relationship. In other words, while all interactions have an interpersonal side, it is the aim of this genre to make possible further interpersonal contact in the first place. The strategies used to create an individual's identity, i.e., how they position themselves within the expectations of the genre of dating ads, are thus critical to the interpersonal relationships that the participants are trying to create. This study therefore examines the interpersonal strategies that dating ad writers use to craft identities as physically and emotionally appealing to their (envisioned) audience.

\section{Concluding remarks}

The contributions to the Handbook of Interpersonal Pragmatics show how the relational aspect of language can be looked at from many different angles. Embracing a definition of pragmatics that allows for this multi-faceted approach, we hope that this collection will (a) given some insights with respect to the importance of the relational aspect of language and its power in shaping discourses and relationships, and (b) make some contributions to our understanding of language and "the full complexity of its cognitive, social, and cultural (i.e. meaningful) functioning in the lives of human beings" (Verschueren 2009: 19, italics removed). The theoretical part of the volume offers insights into several research traditions - from im/politeness theory, communication studies, and social cognition to the study of identity construction and gender. The chapters on linguistic strategies associated with interpersonal effects show how interactants make use of language to convey relational meaning in addition to informational content. Finally, the contributions on particular discourse contexts highlight how complex and dynamic the interpersonal aspect of language in use is. The issues covered in this collection are far from exhaustive. The mere fact that we cannot separate the relational aspect of language from the informational explains that, ultimately, every set of linguistic data can be looked at from the perspective of interpersonal pragmatics. We hope that this handbook will prove to be a valuable starting point for researchers who wish to study the creation of interpersonal meaning, and that it demonstrates the many open questions that remain to be addressed.

\section{Notes}

1. The terms relational and interpersonal are used as synonyms in this chapter.

2. Coulmas (2005: 10) argues that " $[\mathrm{t}]$ he central theme of sociolinguistics is variety. To the observer, language presents itself as a seemingly infinite variety of forms, but this variety is patterned. That is, there are restrictions on choices between coexisting varieties." 
Wardhaugh (2002: 5) tells us that "[a] recognition of [this] variation implies that we must recognize that a language is not just some kind of abstract object of study. It is also something that people use." For our purposes, it is important to point out that the relational aspect of language plays an important role in the search for the cause of the observed variation.

3. Brown and Levinson $(1978,1987)$ argue in their theory of politeness that people estimate the degree of a face-threatening act by taking into account the variables of power, distance and the relative ranking of an imposition in a particular situation and adjust their linguistic behaviour accordingly. Their framework is discussed in detail in Chapter 2 by Maria Sifianou and Chapter 3 by Richard J. Watts.

4. As mentioned before, next to gender, age, ethnicity, and class are considered further important factors in identity construction (cf. De Fina and Mullany, both this volume).

\section{References}

Austin, John L.

1962 How to Do Things With Words. Oxford: Oxford University Press.

Blakemore, Diane

1992 Understanding Utterances. Oxford: Blackwell.

Bousfield, Derek and Miriam A. Locher (eds.)

2008 Impoliteness in Language. Studies on its Interplay with Power in Theory and Practice. Berlin: Mouton de Gruyter.

Brown, Penelope and Stephen C. Levinson

1978 Universals in language usage: Politeness phenomena. In: Esther N. Goody (ed.), Questions and Politeness, 56-289. Cambridge: Cambridge University Press.

Brown, Penelope and Stephen C. Levinson

1987 Politeness. Some Universals in Language Usage. Cambridge: Cambridge University Press.

Brown, Gillian and George Yule

1983 Discourse Analysis. Cambridge: Cambridge University Press.

- Bucholtz, Mary and Kira Hall

2005 Identity and interaction: A sociocultural linguistic approach. Discourse Studies 7(4-5): 585-614.

Coulmas, Florian

2005 Sociolinguistics: The Study of Speakers' Choices. Cambridge: Cambridge University Press.

Crystal, David

1997 The Cambridge Encyclopedia of Language. 2nd ed. Cambridge: Cambridge University Press.

Cummings, Louise

2005 Pragmatics: A Multidisciplinary Perspective. New York: Routledge.

-Davies, Bronwyn and Rom Harré

1990 Positioning: The social construction of self. Journal for the Theory of Social Behavior 20(1): 43-63. 
12 Miriam A. Locher and Sage L. Graham

Davis, Steven

1991 Pragmatics. Oxford: Oxford University Press.

De Fina, Anna

2003 Identity in Narrative. A Study of Immigrant Discourse. Amsterdam: John Benjamins.

Fill, Alwin

1990 Scherz und Streit aus ethnolinguistischer Sicht. Papiere zur Linguistik 2(43): 117-125.

Grice, Herbert Paul

1975 Logic and Conversation. In: Peter Cole and Jerry L. Morgan (eds.), Syntax and Semantics. Vol. III: Speech Acts, 41-58. New York: Academic Press.

Holmes, Janet

1992 An Introduction to Sociolinguistics. London: Longman.

Jucker, Andreas H.

2008 Historical pragmatics. Language and Linguistics Compass 2(5): 894-906.

-Kasper, Gabriele

1990 Linguistic politeness: Current research issues. Journal of Pragmatics 14(2): $193-218$.

Lakoff, Robin

1973 The logic of politeness; or, minding your p's and q's. Papers from the Ninth Regional Meeting of the Chicago Linguistic Society, 292-305. Chicago: Chicago Linguistic Society.

Lakoff, Robin Tolmach

1989 The limits of politeness: Therapeutic and courtroom discourse. Multilingua 8: 101-129.

Leech, Geoffrey N.

1983 Principles of Pragmatics. London: Longman.

Locher, Miriam A. and Derek Bousfield

2008 Introduction: Impoliteness and power in language. In: Derek Bousfield and Miriam A. Locher (eds.), Impoliteness in Language. Studies on its Interplay with Power in Theory and Practice, 1-13. Berlin: Mouton de Gruyter.

Locher, Miriam A. and Richard J. Watts

2008 Relational work and impoliteness: Negotiating norms of linguistic behaviour. In: Derek Bousfield and Miriam A. Locher (eds.), Impoliteness in Language. Studies on its Interplay with Power in Theory and Practice, 77-99. Berlin: Mouton de Gruyter.

-Mao, LuMing Robert

1994 Beyond politeness theory: 'Face' revisited and renewed. Journal of Pragmatics 21(5): 451-486.

-Matsumoto, Yoshiko

1988 Reexamination of the Universality of Face: Politeness Phenomena in Japanese. Journal of Pragmatics 12(4): 403-426.

Schiffrin, Deborah

1994 Approaches to Discourse. Oxford: Blackwell.

Searle, John R.

1969 Speech Acts. An Essay in the Philosophy of Language. Cambridge: Cambridge University Press. 
Taavitsainen, Irma and Andreas H. Jucker

2010 Trends and developments in historical pragmatics. In: Irma Taavitsainen and Andreas H. Jucker (eds.), Handbook of Historical Pragmatics, 3-30. Berlin: De Gruyter Mouton.

Verschueren, Jef

2009 Introduction. The pragmatic perspective. In: Jef Verschueren and Jan Ola Östman (eds.), Key Notions for Pragmatics. Handbook of Pragmatics Highlights, 1-27. Amsterdam: John Benjamins.

Wardhaugh, Ronald

2002 An Introduction to Sociolinguistics. 4th ed. Oxford etc.: Blackwell.

Watzlawick, Paul, Janet Helmick Beavin and Don D. Jackson

1967 Pragmatics of Human Communication. A Study of Interactional Patterns, Pathologies and Paradoxes. New York: Norton. 



\section{Part I: Theoretical approaches to interpersonal pragmatics}

Approaches to politeness and impoliteness 
